\title{
Long Non-Coding RNA HOXA-AS2 Regulates Malignant Glioma Behaviors and Vasculogenic Mimicry Formation via the MiR-373/EGFR Axis
}

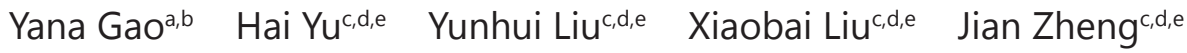 \\ Jun Ma ${ }^{a, b}$ Wei Gong ${ }^{a, b}$ Jiajia Chen ${ }^{a, b}$ Lini Zhao ${ }^{a, b} \quad Y_{\text {Tian }}^{c, d, e} \quad$ Yixue Xue \\ aDepartment of Neurobiology, College of Basic Medicine, China Medical University, Shenyang; \\ ${ }^{b}$ Key Laboratory of Cell Biology, Ministry of Public Health of China, and Key Laboratory of Medical \\ Cell Biology, Ministry of Education of China, China Medical University, Shenyang; 'Department of \\ Neurosurgery, Shengjing Hospital of China Medical University, Shenyang; dLiaoning Clinical Medical \\ Research Center in Nervous System Disease; ${ }^{~}$ Key Laboratory of Neuro-oncology in Liaoning Province, \\ China
}

\section{Key Words}

Glioma • Vasculogenic mimicry $\cdot$ Long non-coding RNA $•$ HOXA-AS2 $・$ MicroRNA $\cdot$ MiR-373 - EGFR

\begin{abstract}
Background/Aims: Vasculogenic mimicry (VM) has been reported to be a novel glioma neovascularization process. Anti-VM therapy provides new insight into glioma clinical management. In this study, we revealed the role of the long non-coding RNA HOXA cluster antisense RNA 2 (HOXA-AS2) in malignant glioma behaviors and VM formation. Methods: Quantitative real-time PCR was performed to determine the expression levels of HOXA-AS2 in glioma samples and glioblastoma cell lines. CD34-periodic acid-Schiff dual-staining was performed to assess VM in glioma samples. CCK-8, transwell, and Matrigel tube formation assays were performed to measure the effects of HOXA-AS2 knockdown on cell viability, migration, invasion, and VM tube formation, respectively. RNA immunoprecipitation, dualluciferase reporter and Western blot assays were performed to explore the molecular mechanisms underlying the functions of HOXS-AS2 in glioblastoma cells. A nude mouse xenograft model was used to investigate the role of HOXA-AS2 in xenograft glioma growth and VM density. Student's t-tests, one-way ANOVAs followed by Bonferroni posthoc tests, and chi-square tests were used for the statistical analyses. Results: HOXA-AS2 was upregulated in glioma samples and cell lines and was positively correlated with VM. HOXA-AS2 knockdown attenuated cell viability, migration, invasion, and VM formation in glioma cells and inhibited the expression of vascular endothelial-cadherin (VE-cadherin), as well as the expression and activity of matrix metalloproteinase matrix metalloproteinase (MMP)-2 and MMP-9. miR-373 was downregulated in glioma samples and cell lines and suppressed malignancy in glioblastoma cells. HOXA-AS2 bound to miR-373 and negatively regulated its expression.


Epidermal growth factor receptor (EGFR), a target of miR-373, increased the expression levels of VE-cadherin, as well as the expression and activity levels of MMP-2 and MMP-9, via activating phosphatidylinositol 3-kinase/serine/threonine kinase pathways. HOXA-AS2 knockdown combined with miR-373 overexpression yielded optimal tumor suppressive effects and the lowest VM density in vivo. Conclusion: HOXA-AS2 knockdown inhibited malignant glioma behaviors and VM formation via the miR-373/EGFR axis.

(C) 2018 The Author(s)

Published by S. Karger AG, Basel

\section{Introduction}

Malignant gliomas are a considerable threat to human health. Despite the improvement in therapeutic approaches, patients with glioblastoma have disappointing median survival times [1]. Angiogenesis contributes significantly to glioma growth, metastasis, and recurrence. However, antiangiogenic therapy, which targets tumor endothelial cells, has limited effects [2]. Vasculogenic mimicry (VM) is described as a novel mechanism of blood supply in gliomas, and endothelium-independent tubular structures are the hallmark of VM $[3,4]$. The presence of VM contributes to more aggressive tumor biology and enhances tumor-related mortality [5, 6]. Previous studies have shown that VM may explain the tumor survival mechanism during antiangiogenic therapy $[7,8]$. Targeting glioma VM has produced treatment effects in animal models [9]. However, more evidence is needed to explain the mechanisms of glioma VM and the effectiveness of anti-VM therapy.

Non-coding RNAs have been demonstrated to be the predominant transcripts of human DNA. Moreover, recent evidence has implicated the involvement of long non-coding RNAs (lncRNAs) in several of the steps leading to glioma development $[10,11]$. The lncRNA HOXA cluster antisense RNA 2 (HOXA-AS2) was first reported to be an apoptosis suppressor in NB4 promyelocytic leukemia cells treated with all-trans retinoic acid [12]. Subsequent studies showed that HOXA-AS2 is aberrantly expressed in several human cancers and functions as an oncogene $[13,14]$. However, little is known concerning its expression in glioma and its potential role in glioma malignancy and VM. Multiple mechanisms are involved in lncRNAmediated tumor biology, among which interactions between lncRNAs and microRNAs are well-studied. By using bioinformatics tools (Starbase 2.0, http://starbase.sysu.edu.cn/), we screened a miRNA candidate, miR-373, which may take part in HOXA-AS2-mediated malignant glioma behaviors and VM formation.

EGFR is a crucial receptor-tyrosine kinase and an active target in glioma treatment [15, 16]. Several studies have shown that EGFR is involved in tumor VM formation. By searching online tools (TargetScan 7.1, http://www.targetscan.org/vert_71/; Miranda, http://www. microrna.org/microrna/home.do), we found that EGFR is a potential target of miR-373, which indicates that miR-373 may regulate the expression and function of EGFR.

In this study, we hypothesized that IncRNA HOXA-AS2 contributes to malignant glioma behaviors and VM formation by acting as a miR-373 sponge. miR-373 targets EGFR and thus decreases the expression levels of vascular endothelial-cadherin (VE-cadherin), as well as suppresses the expression and activity levels of matrix metalloproteinase (MMP)-2 and MMP-9, via inhibiting the PI3K/AKT pathway.

\section{Materials and Methods}

Tissue samples

Normal brain tissues (NBTs) and glioma specimens were collected from the Department of Neurosurgery, Shengjing Hospital of China Medical University. NBTs ( 5 cases) were obtained from surgeries of brain trauma patients. Glioma specimens were divided into two groups, low grade gliomas (LGGs, WHO I-II, 7 cases), high grade gliomas (HGG, WHO III-IV, 10 cases) according to the diagnosis by neuropathologists. After surgical resection, the tissue samples were collected and stored in liquid nitrogen until use. This study was approved by the Ethics Committee of Shengjing Hospital of China Medical University. 


\section{Cellular Physiology Cell Physiol Biochem 2018;45:131-147 \begin{tabular}{l|l|l} 
and Biochemistry $10.1159 / 000486253$ & $\begin{array}{l}\text { D } 2018 \text { The Author(s). Published by S. Karger AG, Basel } \\
\text { www.karger.com/cpb }\end{array}$ \\
\hline
\end{tabular}}

Gao et al.: HOXA-AS2 Regulates Glioma Behaviors and VM Formation

\section{Cell lines and cell culture}

Human glioma cell lines (U87 and U251) and human embryonic kidney cell line HEK-293T were purchased from Shanghai Institutes for Biological Sciences Cell Resource Center. Normal human astrocytes (NHAs) were purchased from Sciencell Research Laboratories (Carlsbad, CA, USA). U87 and HEK-293 T cells were cultured in glucose Dulbecco's modified eagle medium (DMEM) supplemented with $10 \%$ fetal bovine serum (FBS; Life Technologies, Carlsbad, CA). U251 cells were cultured in Dulbecco's modified eagle medium/F12 mixed medium supplemented with 10\% FBS. NHAs were cultured in astrocyte medium (Carlsbad, CA, USA). All cells were cultured at $37^{\circ} \mathrm{C}$ in a humidified incubator containing $5 \% \mathrm{CO}$.

\section{Quantitative reverse-transcriptase polymerase chain reaction ( $q R T-P C R$ )}

Total RNA was isolated using the Trizol reagent (Life Technologies Corporation). For quantification of HOXA-AS2 and Glyceraldehyde 3-phosphate dehydrogenase (GAPDH) mRNA, One-Step SYBR PrimeScript RTPCR Kit (Perfect Real Time; Takara Bio, Inc., Japan) were used according to the manufacturer's instructions. TaqMan MicroRNA Reverse Transcription kit and Taqman Universal Master Mix II (Applied Biosystems, Foster City, CA, USA) were used to detect miR-373 and U6. GAPDH and U6 were used as endogenous controls, respectively. Fold change was calculated as $2^{-\Delta \Delta C t}$ in gene expression. Primers sequence: HOXA-AS2, forward:

TGAACCAGGAATTGTCTCCA, reverse: CATCTCCCACTCCCAGAAAG; GAPDH: forward: GGTGAAGGTCGGAGTCAACG, reverse: CCATGTAGTTGAGGTCAATGAAG. Probe: miR-373: 478073 (Applied biosystems); U6: 001973 (Applied biosystems).

\section{CD34- periodic acid-schiff (PAS) dual-straining}

For CD34 (1:50, Santa Cruz Biotechnology, Santa Cruz, CA, USA, sc-74499) straining, standard immunohistochemical staining was performed according to the manufacture's instruction (Maixin Biotechnology Co. Ltd, Fuzhou, China). After strained with 3, 3'-diaminobenzidine, sections were further stained with PAS followed by counterstaining with hematoxylin. Sections were imaged under a light microscope (Olympus, Japan). The VM density was evaluated by three independent observers without knowledge of the outcome.

\section{Cell transfection}

The short hairpin RNA against human HOXA-AS2 (Genebank: NR_122069.1) gene or human EGFR (Genebank: NM_005228.4) gene was reconstructed in a pGPU6/Neo vector, respectively (sh-HOXA-AS2, sh-EGFR; GenePharma, Shanghai, China), and its empty vector was used as a negative control (NC) (shNC). Human EGFR gene coding sequence was ligated into pIRES2-EGFP vector, (GeneScript, Piscataway, NJ, USA), and its empty vector was used as a NC (EGFR-NC). Glioma cells were seeded in 24-well plates and transfected using Lipofectamine 3000 and P3000 reagents (Invitrogen, CA, USA) when the confluence reached at $\sim 70 \%$. Stable transfected cell lines were selected by the medium supplemented with Geneticin (G418; Sigma-Aldrich, St Louis, MO, USA), G418-resistant glioma cells were obtained after 4 weeks. The transfection of MiRNAs was performed by using agomir-373, antagomir-373, and their respective NC (GenePharma, Shanghai, China), according to the manufacture's instruction. 48 hours after transfection, cells were collected for the subsequent assay. Sequences of shRNA: sh-HOXA-AS2:GCCGTCAGAATCCAAGTGAAT, sh-EGFR:GCGTCCGCAAGTGTAAGAAGT,

Negative Control: GTTCTCCGAACGTGTCACGT.

Cell proliferation assay

Cell proliferation assay was performed by using Cell Count Kit-8 (CCK-8, Beyotime Institute of Biotechnology, Jiangsu, China). Briefly, glioma cells were digested and seeded in 96 -well plates at the density of $2000 /$ well. After cultured for $48 \mathrm{~h}, 10 \mu \mathrm{L}$ of CCK- 8 were added into each well and incubated at $37^{\circ} \mathrm{C}$ for 2 h. The absorbance was measured at $450 \mathrm{~nm}$.

\section{Cell migration and invasion assays}

The transwell chamber assay was performed to examine the migration and invasion inability of glioma cells in vitro. Cells were added in the upper chamber of a 24-well transwell unit $\left(2 \times 10^{4}\right.$ cells/well $)$ with $8 \mu \mathrm{m}$ pore size polycarbonate membrane (Corning Costar, Cambridge, MA, USA). The upper chamber contained serum-free medium, while the lower compartment contained medium with $10 \% \mathrm{FBS}$; After incubated for 


\section{Cellular Physiology Cell Physiol Biochem 2018;45:131-147 \begin{tabular}{ll|l} 
DOI: 10.1159/000486253 & $\begin{array}{l}\text { O 2018 The Author(s). Published by S. Karger AG, Basel } \\
\text { www.karger.com/cpb }\end{array}$ \\
\hline
\end{tabular}}

Gao et al.: HOXA-AS2 Regulates Glioma Behaviors and VM Formation

$24 \mathrm{~h}$ in a humidified atmosphere of $5 \% \mathrm{CO} 2$ at $37^{\circ} \mathrm{C}$, the cells adhering to the lower surface of the filter were fixed and stained with Giemsa. For the invasion assay, the upper surface of the filter was precoated with 500 $\mathrm{ng} / \mu \mathrm{l}$ matrigel solution (BD Biosciences, San Jose, CA, USA). The cells were treated in the same way as the migration assay. Strained cells from at least five random fields were counted.

\section{In vitro tube formation assay}

Glioma cells tube formation assay was performed as described previously [4]. Briefly, 24-well plates were coated with Matrigel (100 $\mu \mathrm{l} /$ well, BD Bioscience) and then incubated at $37{ }^{\circ} \mathrm{C}$ for $30 \mathrm{~min}$. Then, glioma cells were resuspended in $100 \mu \mathrm{l}$ complete DMEM at a density of $2 \times 10^{5}$ cells per ml and added to Matrigel-coated wells. After maintained in $37{ }^{\circ} \mathrm{C}$ for $24 \mathrm{~h}$, photos were collected using Olympus DP71 immunofluorescence microscopy (Olympus, Tokyo, Japan). The number of tubular structures in five random fields was quantified using Chemi Imager 5500 V2.03 software.

\section{Western blot analysis}

After cell transfection or treatment with PI3Kinhibitor (LY294002, Beyotime Institute of Biotechnology), cells were collected, and proteins were isolated using RIPA buffer (Beyotime Institute of Biotechnology). After electrophoresis and transferred to a polyvinylidenedifluoride membrane (Millipore, Shanghai, China), the proteins were incubated with primary antibodies (VE-cadherin, 1:1000, Abcam, Cambridge, UK, ab33168, MMP2, 1:1000, proteintech, Wuhan, China, 10373-2-AP; MMP9, 1:1000, proteintech, 10375-2AP; EGFR, 1:1000, proteintech, 18986-1-AP; PI3K, 1:1000, proteintech, 20584-1-AP; p-PI3K, 1:1000, Cell Signaling Technology, Beverly, MA, USA, \#4228, AKT, 1:1000, proteintech, 10176-2-AP; p-AKT, 1:1000, Cell Signaling Technology, \#9271; GAPDH, 1:200, Santa Cruz Biotechnology, sc-32233) overnight at $4^{\circ} \mathrm{C}$. The membranes were then incubated with respective secondary antibodies for $2 \mathrm{~h}$ at room temperature. Bands were visualized using enhanced chemiluminescence (Beyotime Institute of Biotechnology).

\section{Gelatin zymography assay}

Zymogram gels were loaded with equal protein amounts. Samples were electrophoretically separated on $8 \%$ sodium dodecyl sulfate polyacrylamide gels (SDS-PAGE) containing gelatin $(1 \mathrm{mg} / \mathrm{ml}$, Invitrogen, Carlsbad, CA, USA) under nonreducing condition. After washed twice in $2.5 \%$ Triton X-100, the gels were then incubated for $24 \mathrm{~h}$ with $50 \mathrm{mmol} / \mathrm{l}$ Tris-HCl buffer (pH 7.5; containing $0.2 \mathrm{~mol} / \mathrm{l} \mathrm{NaCl}$ and $10 \mathrm{mmol} / \mathrm{l}$ $\mathrm{CaCl} 2$ ). After incubation, Gels were stained with Brilliant Blue R250 and destained. MMP-2 and MMP-9 gelatinolytic bands were visualized on a dark blue background. Band densitometry was determined using Chemilmager 5500 V2.03 software.

\section{Luciferase reporter assays}

The fragment from HOXA-AS2 containing the predicted miR-373 binding site and its mutant sequence were amplified by PCR, synthesized and cloned into the pmirGLO dual-luciferase vector (Promega, Madison, WI, USA). Similarly, the fragment from EGFR 3'-untranslated regions containing the predicted miR-373 binding site and its mutant sequence were also clone into the above vector. The vectors and agomir-373 or agomir-373-NC were co-transfected into HEK293T cells. Luciferase activity was measured $48 \mathrm{~h}$ after transfection through the Dual-Luciferase Reporter System (Promega).

\section{Subcutaneous and orthotopic xenografts in nude mice}

All the animal experiments were conducted in accordance with the Animal Welfare Act and were reviewed and approved by the Ethics Committee of Shengjing Hospital. 4-6 weeks old male BALB/c athymic nude mice were purchased from Cancer Institute of the Chinese Academy of Medical Science. Mice were randomized in each double-blind group by three performers, $n=7$ per group.

To establish subcutaneous xenografts, $5 \times 10^{5}$ glioma cells were inoculated in the right flank of each mouse. Tumor volumes [(length $\times$ width $\left.^{2}\right) / 2$ ] were measured by caliper every 4 day until 45 days postinoculation. To establish orthotopic xenografts, $1 \times 10^{6}$ cells were injected into the right striatum of the nude mice. The number of survived mice was recorded daily until 45 days when most mice sacrificed. Survival analysis was performed using Kaplane Meier survival curve. Orthotopic xenografts were collected for the CD34-PAS dual-straining. 


\section{Cellular Physiology Cell Physiol Biochem 2018;45:131-147

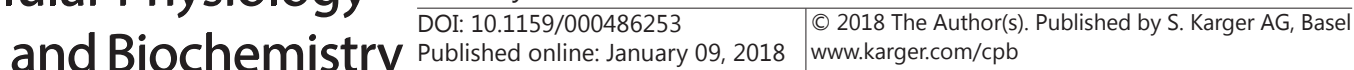

Gao et al.: HOXA-AS2 Regulates Glioma Behaviors and VM Formation

Statistical analysis

Statistical analysis was performed using GraphPad Prism v5.01. Multiple group comparisons were performed by using a one-way analysis of variance (ANOVA) test followed by Dunnett's post-hoc test. Descriptive data are presented as the mean \pm SD from at least three independent experiments. Differences were considered significant at $P$ values of $<0.05$.

\section{Results}

HOXA-AS2 was upregulated in glioma samples and glioblastoma cell lines and was positively correlated with glioma VM

To clarify the potential role of HOXA-AS2 in glioma, quantitative real-time PCR (qRT-PCR) was first performed to evaluate the expression of HOXA-AS2 in normal brain tissues(NBTs), low-grade gliomas (LGGs) (grade I-II), high-grade gliomas (HGGs) (grade III-IV), normal human astrocytes (NHAs) and U87 and U251 glioblastoma cell lines. As shown in Fig. 1 A, compared with NBTs, HOXA-AS2 was upregulated in the glioma samples. The expression levels of HOXA-AS2 were also significantly higher in U87 and U251 cell lines than those in the NHAs (Fig. 1 B). To verify the correlation between HOXA-AS2 and glioma VM, CD34-periodic acid-Schiff (PAS) dual-straining was performed. As shown in Fig. 1 C, CD34-negative and PSA-positive channels were considered to be VM. In addition, VM was observed in 3 of the 10 cases of high-grade gliomas. Remarkably, HOXA-AS2 expression levels were higher in the VM-positive group than in the VM-negative group. (Fig. 1 D). Collectively, increased HOXAAS2 levels may predict glioma VM.

HOXA-AS2 knockdown inhibited glioma cell malignant behaviors andVM formation and reduced the expression levels of VE-cadherin, as well as the expression and activity levels of MMP-2 and MMP-9

Stable HOXA-AS2-knockdown U87 and U251 cells were created to identify the roles of HOXA-AS2 in glioma cells. The transfection efficiency of sh-HOXA-AS2 was shown in Fig. 1 E. The viability of U87 and U251 cells was significantly lower in the sh-HOXA-AS2 groups than that in the sh-NC groups (Fig. 1 F). Similar to the effects on cell viability, HOXA-AS2 knockdown inhibited U87 and U251 cell migration and invasion (Fig. $1 \mathrm{G}$ ). In vitro VM tube formation assays showed that HOXA-AS2 knockdown decreased tube formation in U87 and U251 cells (Fig. $1 \mathrm{H}$ ). The above findings indicated that HOXA-AS2 knockdown suppressed glioma malignancy and VM formation.

MMP-2, MMP-9, and VE-cadherin participate in a crucial signalling pathway in glioma progression and VM formation [17]. Thus, the current study focused on these proteins to investigate the underlying mechanism of HOXA-AS2-mediated glioma biology. Western blot results showed that the protein levels of VE-cadherin, MMP-2, and MMP-9 in U87 and U251 cells were lower in the sh-HOXA-AS2 groups than in the sh-NC groups (Fig. 1 I). In addition, gelatin zymography assays showed that the enzymatic activity levels of MMP-2 and MMP-9 were impaired in the sh-HOXA-AS2 groups (Fig. $1 \mathrm{~J}$ ).

HOXA-AS2 negatively regulated and bound to miR-373

miR-373 expression levels were measured in U87 and U251 cells in which HOXAAS2 was stably knocked down. As shown in Fig. 2 A, miR-373 was upregulated in U87 and U251 cells in the sh-HOXA-AS2 groups. IncRNAs can sponge miRNAs and regulate their functions. The potential binding site of miR-373 in HOXA-AS2 was predicted by an online tool (Starbase). Subsequently, dual-luciferase reporter assays were performed to confirm the possible binding site. As shown in Fig. 2 B, luciferase activity was lower in the HOXAAS2-wt+pre-miR-373 group than in the HOXA-AS2-wt+pre-NC group in HEK293T cells. Furthermore, RNA immunoprecipitation (RIP) assays showed that the relative enrichment of HOXA-AS2 and miR-373 was higher in the Ago2 immunoprecipitants than in the IgG immunoprecipitants. Moreover, in U87 and U251 cells, miR-373 knockdown decreased the 
Fig. 1. The expression levels of HOXAAS2 in glioma and its correlation with glioma VM. (A) The expression of HOXAAS2 in normal brain tissues (NBTs) and glioma tissues. Data were presented as mean \pm SD from three independent experiments ( 5 cases in NBTs groups, 7 cases in low grade glioma group (LGGs) and 10 cases in high grade glioma (HGGs) group). ${ }^{*} \mathrm{P}<0.05$ and $* * \mathrm{P}<0.01$ v.s. NBTs group, ${ }^{\#} \mathrm{P}<0.05$ v.s. LGGs group. (B) The expression levels of HOXA-AS2 in normal human astrocytes (NHA) and glioma cell lines. Data were presented as mean \pm SD from four independent experiments ${ }^{\&} \mathrm{P}<0.05$ v.s. NHA group. (C) CD34-negative and periodic acid-schiffpositive channels in HGGs. (D) Comparing expression of HOXA-AS2 between VM-negative tissues and VM-positive tissues. ${ }^{\wedge} \mathrm{\Delta} p<0.01$ v.s. VM (-) group. (E) HOXA-AS2 was
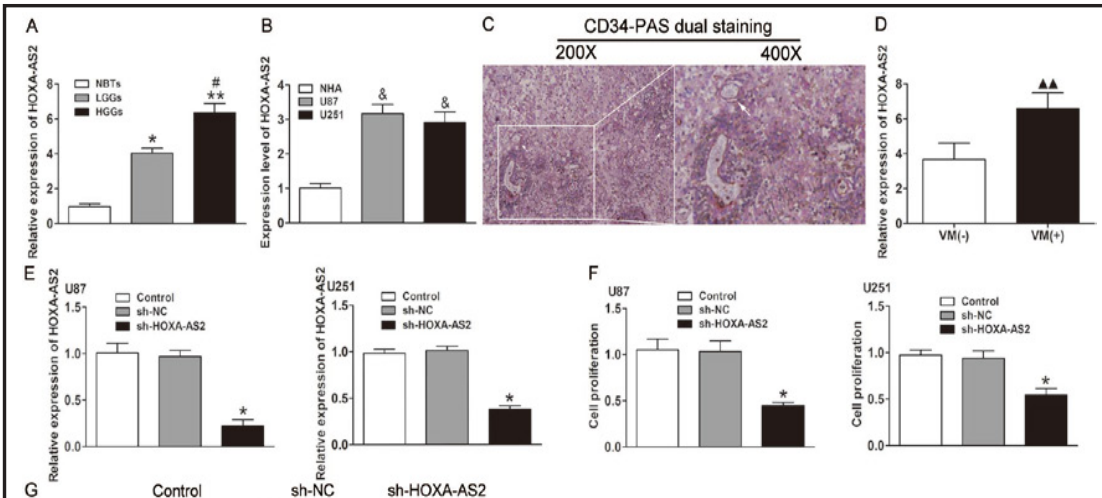

G
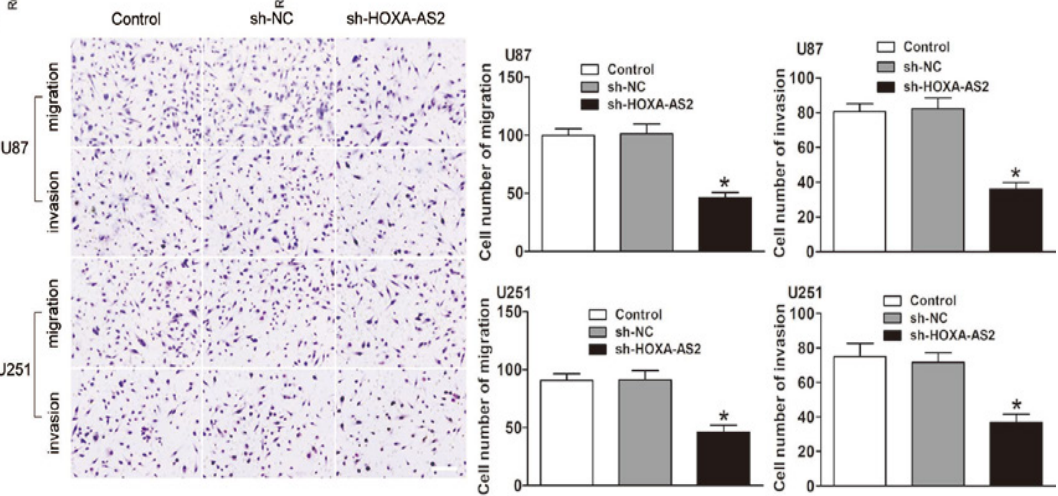

$\mathrm{H}$
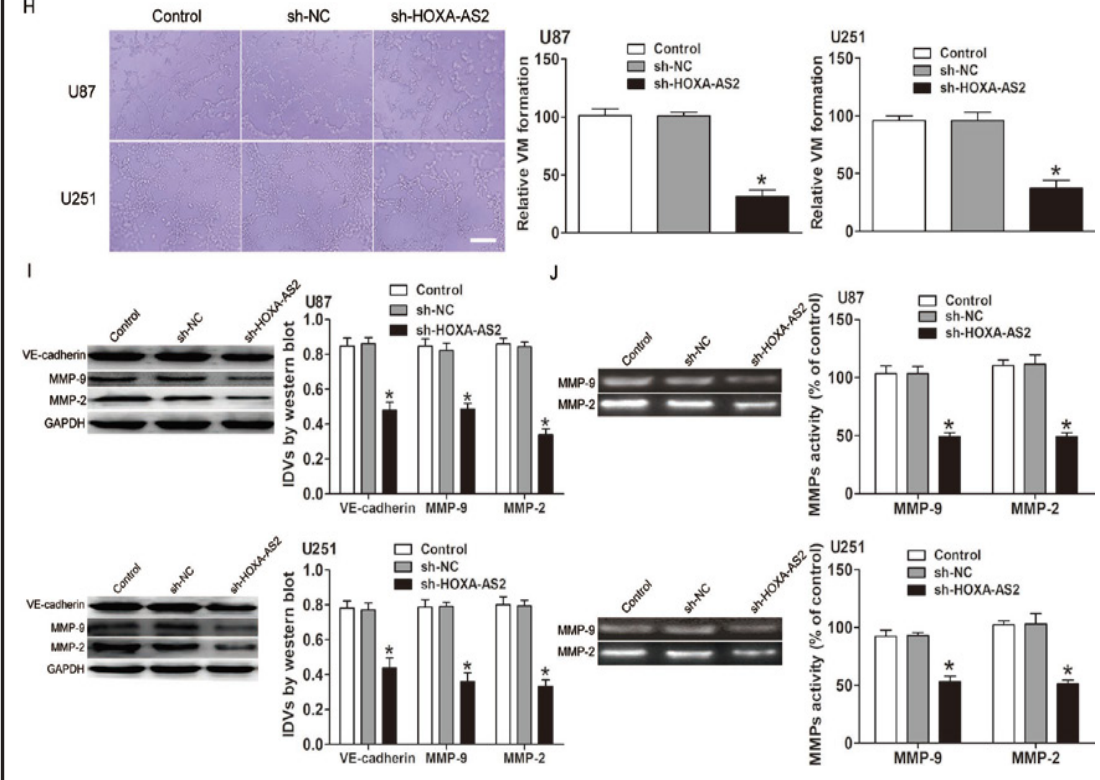

knocked down in

U87 and U251 cells. HOXA-AS2 expression levels were determined by qRT-PCR. (F) Cell proliferation was measured by CCK-8. (G) The migration and invasion were measured by transwell assays. (H) The VM formation was measured by Matrigel tube formation assay. (I) The protein expression level of VE-cadherin, MMP2 and MMP-9 was analyzed by Western blot. (J) The enzymatic activity of MMP2 and MMP9 was analyzed by gelatin zymography assay. Data were presented as mean \pm SD from four independent experiments. $* \mathrm{P}<0.05$ v.s. sh-NC groups.

enrichment of both HOXA-AS2 and miR-373 in the Ago2 immunoprecipitants (Fig. 2 C). The above results indicated that HOXA-AS2 negatively regulated miR-373 via binding to it in a sequence-specific manner. 


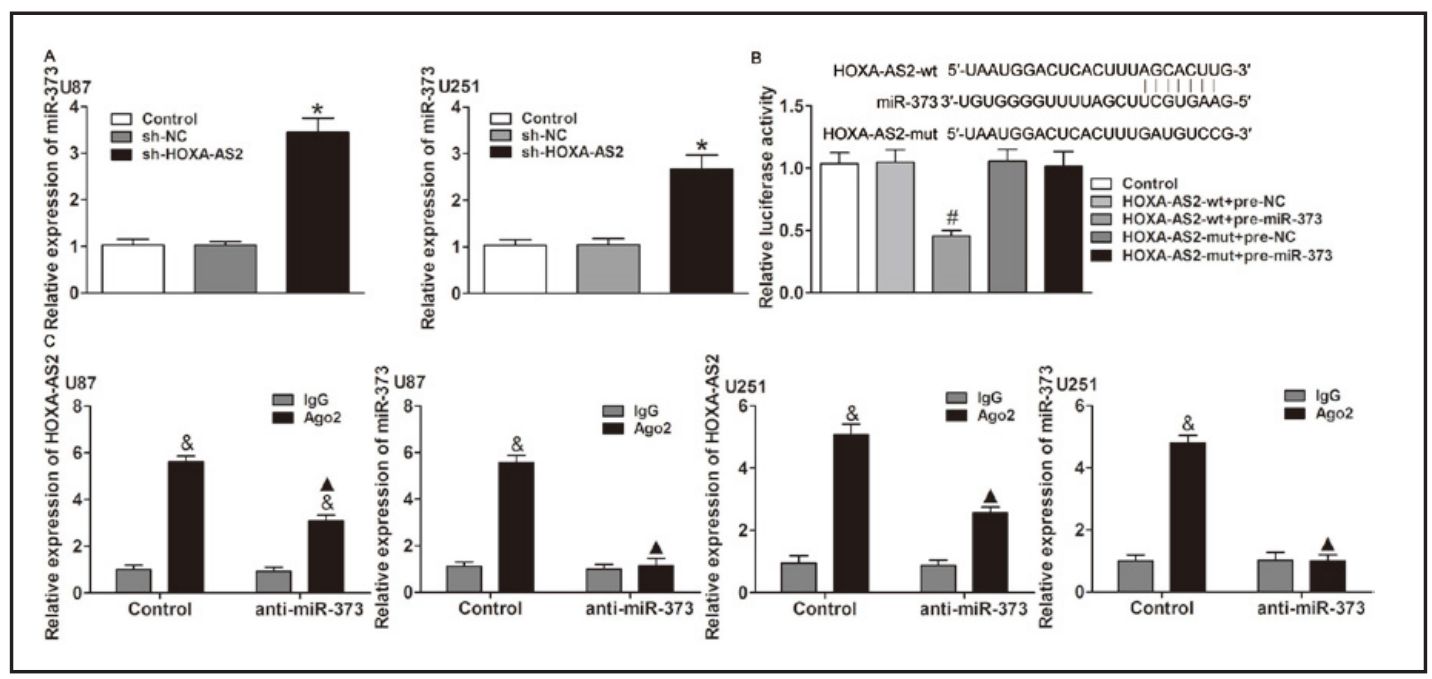

Fig. 2. HOXA-AS2 negatively regulated miR-373 and bound to miR-373. (A) HOXA-AS2 was knocked down in U87 and U251 cells. The expression level of miR-373 was analyzed by quantitative real-time PCR. Data were presented as mean \pm SD from four independent experiments. ${ }^{*} \mathrm{P}<0.05$ v.s. sh-NC groups (B) Overexpression of miR-373 significantly suppressed the luciferase activity of HOXA-AS2-wt but not HOXA-AS2-mut. Data were presented as mean \pm SD from three independent experiments. \#p <0.05 v.s. HOXA-AS2-mut+premiR-373 group. (C) Relative enrichment of HOXA-AS2 and miR-373 in Ago2 immunoprecipitates and IgG immunoprecipitates were measured by quantitative real-time PCR. Data were presented as mean \pm SD from three independent experiments. ${ }^{\&} \mathrm{P}<0.01$ v.s. IgG groups, ${ }^{\wedge} \mathrm{P}<0.05$ v.s. Control groups.

miR-373 was a tumor suppressor and downregulated the expression of VE-cadherin, as well as the expression and activity levels of MMP-2 and MMP-9

The expression levels of miR-373 in glioma samples and glioma cell lines were determined by qRT-PCR. As shown in Fig. 3 A-B, miR-373 was downregulated in the glioma samples and U87 and U251 cell lines. To further explore the functional role of miR373, agomir-373, antagomir-373, and their respective negative controls were transfected into U87 and U251 cells. The transfection efficiency of miR-373 was shown in Fig. $3 \mathrm{C}$. Overexpression of miR-373 decreased the proliferation (Fig. 3 D), migration, invasion (Fig. 3 E), and VM formation (Fig. 3 F) inU87 and U251 cells. Opposite effects were observed in the anti-miR-373 group. Subsequent Western blot results showed that miR-373 overexpression inhibited the expression of VE-cadherin, MMP-2, and MMP-9 and that miR-373 knockdown enhanced the expression of these proteins (Fig. 3 G). Moreover, miR-373 overexpression increased the activity levels of MMP-2 and MMP-9 (Fig. $3 \mathrm{H}$ ). The above findings indicated that miR-373 exerted a tumor suppressive function via negatively regulating VE-cadherin, MMP-2, and MMP-9.

miR-373 was involved in HOXA-AS2-mediated glioma malignant behaviors and regulating VE-cadherin, MMP-2, and MMP-9

To explore whether miR-373 was involved in the tumor-suppressive effects of HOXA-AS2 knockdown, co-transfection assays were performed. As shown in Fig. 4 A-C, the combination of HOXA-AS2 knockdown and miR-373 overexpression enhanced the suppressive effects on cell viability, migration, invasion, and VM formation in U87 and U251 cells, which were induced by HOXA-AS2 knockdown or miR-373 overexpression alone. In addition, the co-transfection of sh-HOXA-AS2 and anti-miR-373 reversed the reduction in glioma cell malignancy induced by HOXA-AS2 knockdown and the induction of glioma cell malignancy induced by miR-373 knockdown. Similar to the functional assays, the co-transfection of sh- HOXA-AS2 and pre-miR-373 increased the inhibitory effects on the expression of VEcadherin and the expression and activity levels of MMP-2 and MMP-9, which were induced 


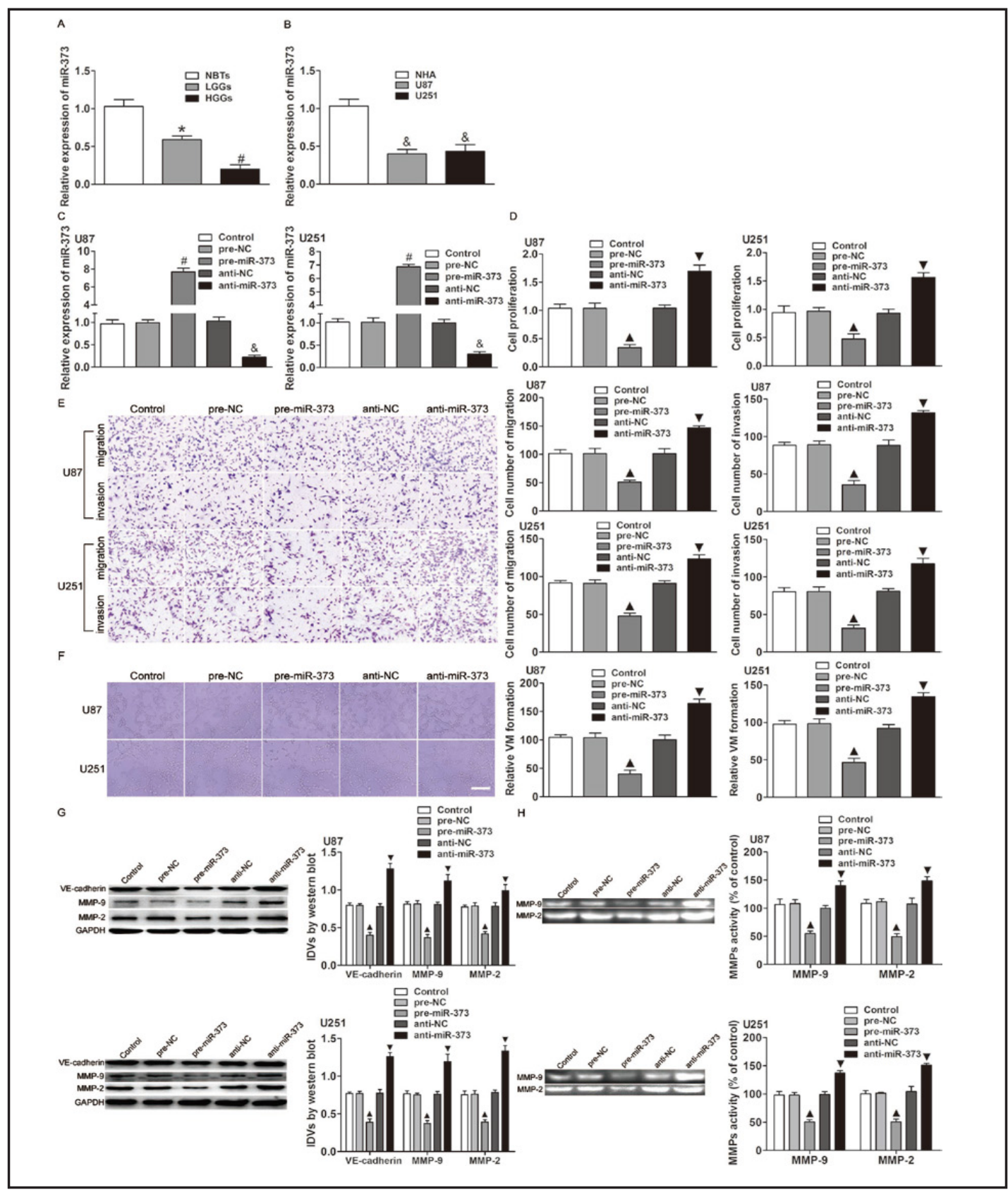

Fig. 3. miR-373 was a tumor suppressor and downregulated the expression of VE-cadherin, the expression and activity of MMP-2, and MMP-9. (A) The expression of miR-373 in normal brain tissues (NBTs) and glioma tissues. Data were presented as mean \pm SD from three independent experiments (5 cases in NBTs groups, 7 cases in low grade glioma group (LGGs) and 10 cases in high grade glioma (HGGs) group). ${ }^{*} \mathrm{P}$ $<0.05$ and ${ }^{* *} \mathrm{P}<0.01$ v.s. NBTs group, ${ }^{*} \mathrm{P}<0.05$ v.s. LGGs group. (B) The expression of miR-373 in normal human astrocytes (NHA) and glioma cell lines. Data were presented as mean \pm SD from four independent experiments ${ }^{\circledR} \mathrm{P}<0.05$ v.s. NHA group. miR-373 was overexpressed and downregulated in U87 and U251 cells. (C)miR-373 expression levels were determined by qRT-PCR. (D) Cell proliferation was measured by CCK-8. (E) The migration and invasion were measured by transwell assays. (F) The VM formation was measured by Matrigel tube formation assay. (G) The protein expression level of VE-cadherin, MMP-2 and MMP-9 was analyzed by Western blot. (H) The enzymatic activity of MMP-2 and MMP-9 was analyzed by gelatin zymography assay. Data were presented as mean \pm SD from four independent experiments. ${ }^{\wedge} \mathrm{P}<0.05$ v.s. pre-NC groups. ${ }^{\mathbf{P}}<0.05$ v.s. anti-NC groups.

\section{KARGER}




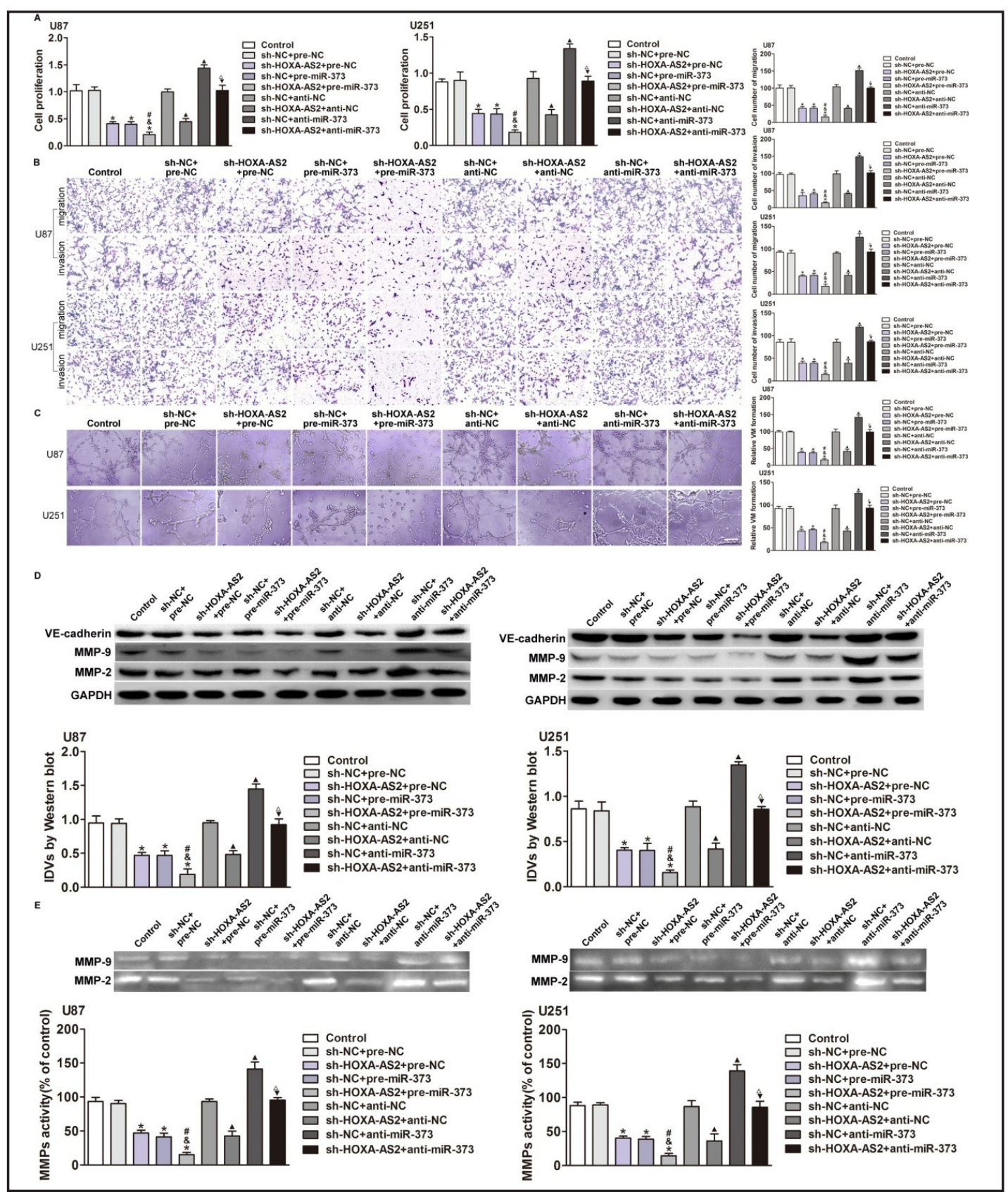

Fig. 4. miR-373 was involved in HOXA-AS2-mediated glioma malignant behaviors and regulation of VEcadherin, MMP-2, and MMP-9. (A) Stable HOXA-AS2 knocked down U87 and U251 cells were transfected with agomir-373 or antagomir-373. Cell proliferation was measured by CCK-8. (B) The migration and invasion were measured by transwell assays. (C) The VM formation was measured by Matrigel tube formation assay. (D) The protein expression level of VE-cadherin, MMP-2 and MMP-9 was analyzed by Western blot. (E) The enzymatic activity of MMP-2 and MMP-9 was analyzed by gelatin zymography assay. Data were presented as mean \pm SD from four independent experiments. ${ }^{*} \mathrm{P}<0.05$ v.s. sh-NC+pre-NC groups, ${ }^{~} \mathrm{P}<0.05$ v.s. sh-HOXAAS2+pre-NC groups, ${ }^{\&} \mathrm{P}<0.05$ v.s. sh-NC+pre-miR-373 groups, ${ }^{\Delta} \mathrm{P}<0.05$ v.s. sh-NC+anti-NC groups, ${ }^{\Delta} \mathrm{P}<0.05$ v.s. sh-HOXA-AS2+anti-NC groups, $\mathbf{P}<0.05$ v.s. sh-NC+anti-miR-373 groups.

by HOXA-AS2 knockdown or miR-373 overexpression alone. Moreover, the combination of HOXA-AS2 knockdown and miR-373 knockdown reversed the decrease in VE-cadherin expression levels and MMP-2 and MMP-9 expression and activity levels induced by HOXA-

\section{KARGER}




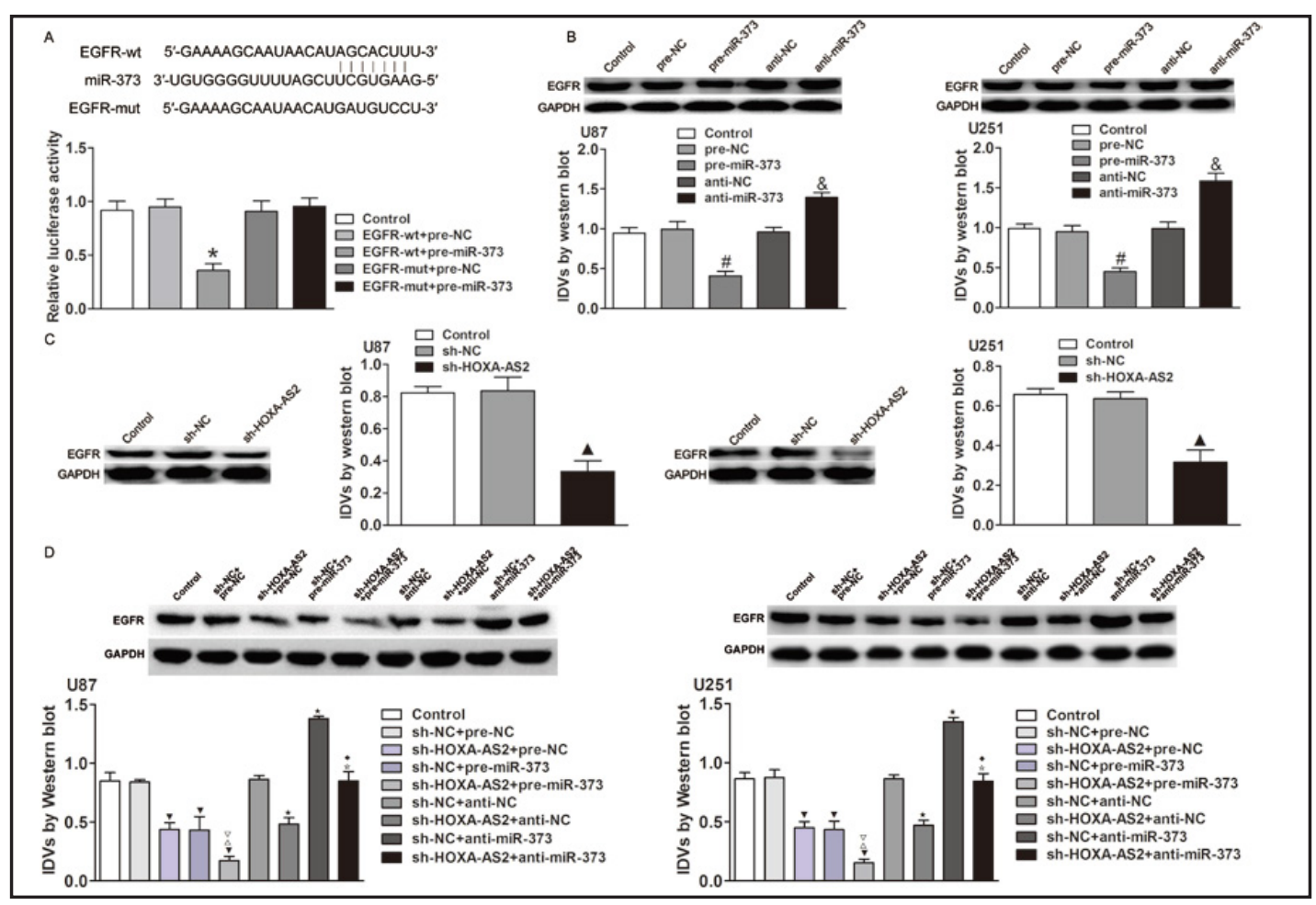

Fig. 5. EGFR was a target of miR-373. (A) Overexpression of miR-373 significantly suppressed the luciferase activity of wt 3'-UTR of EGFR but not mut 3'-UTR of EGFR. Data were presented as mean \pm SD from three independent experiments. ${ }^{*} \mathrm{P}<0.05$ v.s. EGFR3'-UTR-mut+pre-miR-373 group. (B) miR-373 was overexpressed and downregulated in U87 and U251 cells. The protein expression level of EGFR was analyzed by Western blot. (C) HOXA-AS2 was knocked down in U87 and U251 cells. The protein expression level of EGFR was analyzed by Western blot. (D) Stable HOXA-AS2 knocked down U87 and U251 cells were transfected with agomir-373 or antagomir-373. The protein expression level of EGFR was analyzed by Western blot. Data were presented as mean \pm SD from four independent experiments. $\mathrm{P}<0.05$ v.s. pre$\mathrm{NC}$ groups, ${ }^{\&} \mathrm{P}<0.05$ v.s. anti-NC groups, ${ }^{\Delta} \mathrm{P}<0.05$ v.s. sh-NC groups, ${ }^{\mathbf{v}} \mathrm{P}<0.01$ v.s. sh-NC+pre-NC groups. $\nabla \mathrm{P}<0.05$ v.s. sh-NC+pre-NC groups, $\nabla^{\nabla} \mathrm{P}<0.05$ v.s. sh-HOXA-AS2+pre-NC groups, ${ }^{\triangle} \mathrm{P}<0.05$ v.s. sh-NC+premiR-373 groups, ${ }^{\star} \mathrm{P}<0.05$ v.s. sh-NC+anti-NC groups, ${ }^{\star} \mathrm{P}<0.05$ v.s. sh-HOXA-AS2+anti-NC groups, ${ }^{\star} \mathrm{P}<0.05$ v.s. sh-NC+anti-miR-373 groups.

AS2 downregulation, as well as the increase in VE-cadherin expression levels and MMP-2 and MMP-9 expression and activity levels induced by miR-373 downregulation (Fig. 4 D-E). The above data indicated that the tumor-suppressive effects, the inhibition of VE-cadherin expression, and the inhibition of MMP- 2 and MMP-9 expression and activity induced by HOXA-AS2 knockdown were mediated by miR-373 in glioma cells.

\section{EGFR was a target of miR-373}

It is widely accepted that miRNAs inhibit gene expression via an RNA-induced silencing complex [18]. Online tools show that the 3'-untranslated region (UTRs) of VE-cadherin, MMP-2, and MMP-9 do not have a miR-373 putative binding site, which indicates that miR373 regulates VE-cadherin, MMP-2, and MMP-9 in an indirect way. By searching online tools, EGFR was screened to be a potential target of miR-373. Subsequently, we performed dualluciferase reporter assays to confirm the above binding site. As shown in Fig. 5 A, luciferase activity in the HEK293T cells co-transfected with EGFR-wt and pre-miR-373was lower than in the cells co-transfected with EGFR-wt and pre-NC. Furthermore, Western blot assays showed that miR-373 overexpression inhibited the expression of EGFR in U87 and U251 cells, and opposite effects were observed in the miR-373 knockdown group (Fig. 5 B). In addition, HOXA-AS2 knockdown decreased EGFR expression levels in U87 and U251 cells 


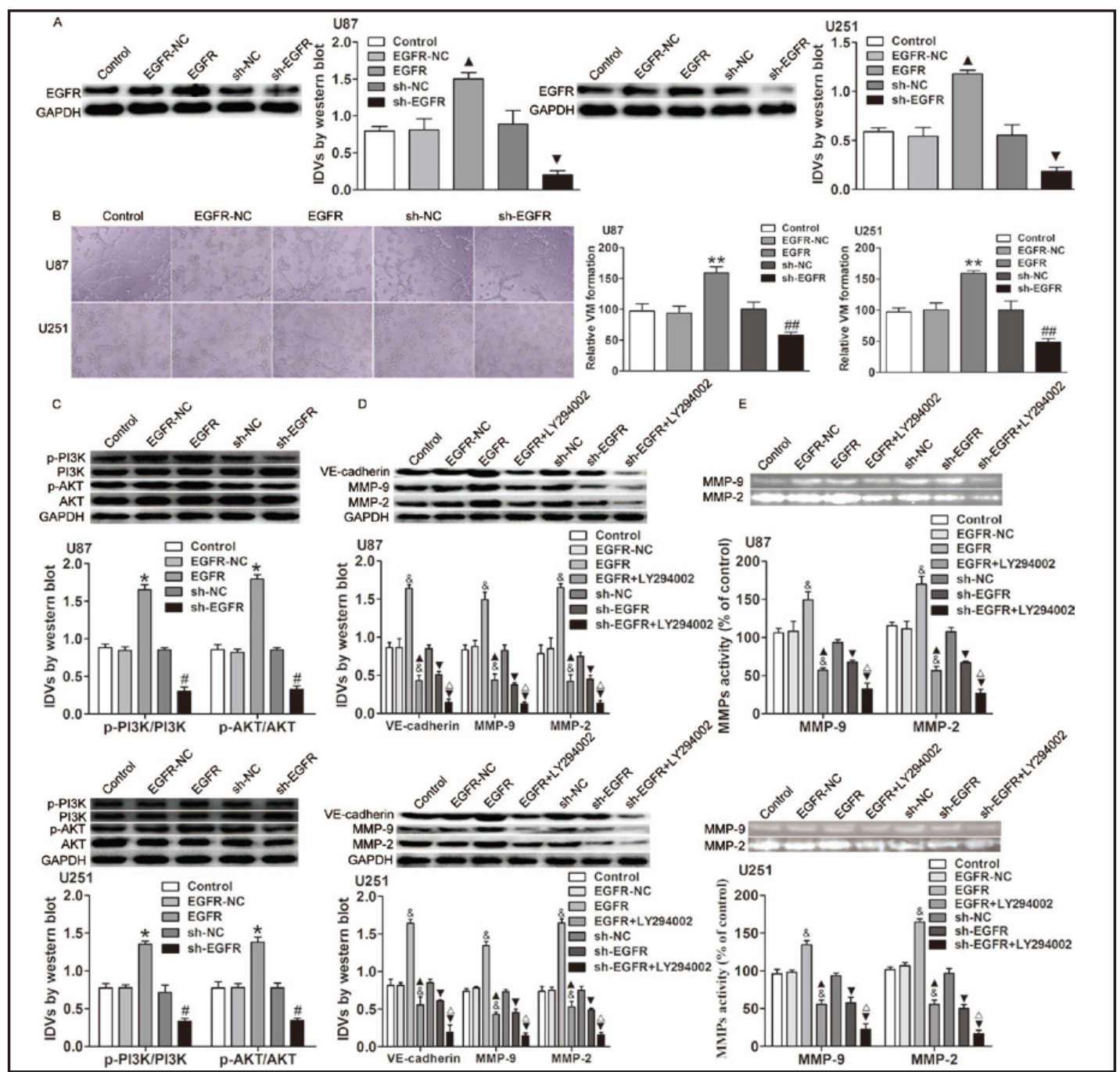

Fig. 6. EGFR increased glioma cells VM formation and the expression of VE-cadherin, and the expression and activity of MMP-2 and MMP-9 by activating PI3K/AKT pathway. EGFR was overexpressed and downregulated in U87 and U251 cells. (A) EGFR expression levels were determined by Western blot. (B) The VM formation was measured by Matrigel tube formation assay. Data were presented as mean \pm SD from three independent experiments $^{\wedge} \mathrm{P}<0.05$ v.s. EGFR-NC groups, ${ }^{\mathbf{}} \mathrm{P}<0.05$ v.s. sh-NC groups. ${ }^{* *} \mathrm{P}<0.01$ v.s. EGFR-NC groups, \#\#P $<0.01$ v.s. sh-NC groups. (C) The PI3K/AKT pathway was analyzed by Western blot. Data were presented as mean \pm SD from four independent experiments. ${ }^{*} \mathrm{P}<0.05$ v.s. EGFR-NC groups, ${ }^{\#} \mathrm{P}<0.05$ v.s. sh-NC groups (D) PI3K inhibitor (LY294002) was introduced in U87 and U251 cells that stably overexpressed or knocked down EGFR. The protein expression level of VE-cadherin, MMP-2 and MMP-9 was analyzed by Western blot. (E) The enzymatic activity of MMP-2 and MMP-9 was analyzed by gelatin zymography assay. Data were presented as mean \pm SD from four independent experiments. ${ }^{\&} \mathrm{P}<0.05$ v.s. EGFR-NC groups, ${ }^{\wedge} \mathrm{P}<0.01$ v.s. EGFR groups, ${ }^{\nabla} \mathrm{P}<0.05$ v.s. sh-NC groups, ${ }^{\Delta} \mathrm{P}<0.05$ v.s. sh-EGFR groups.

(Fig. 5 C), and miR-373 was involved in the above effects (Fig. 5 D). These findings revealed that HOXA-AS2 knockdown inhibited EGFR expression levels via upregulating miR-373.

EGFR enhanced glioma VM formation and increased the expression levels of VE-cadherin, as well as the expression and activity levels of MMP-2 and MMP-9, by activating the PI3K/ AKT pathway

EGFR promotes malignant behaviors in glioma cells [19]. To determine whether EGFR regulates glioma VM formation, gain- and loss-of-function assays were performed. The 


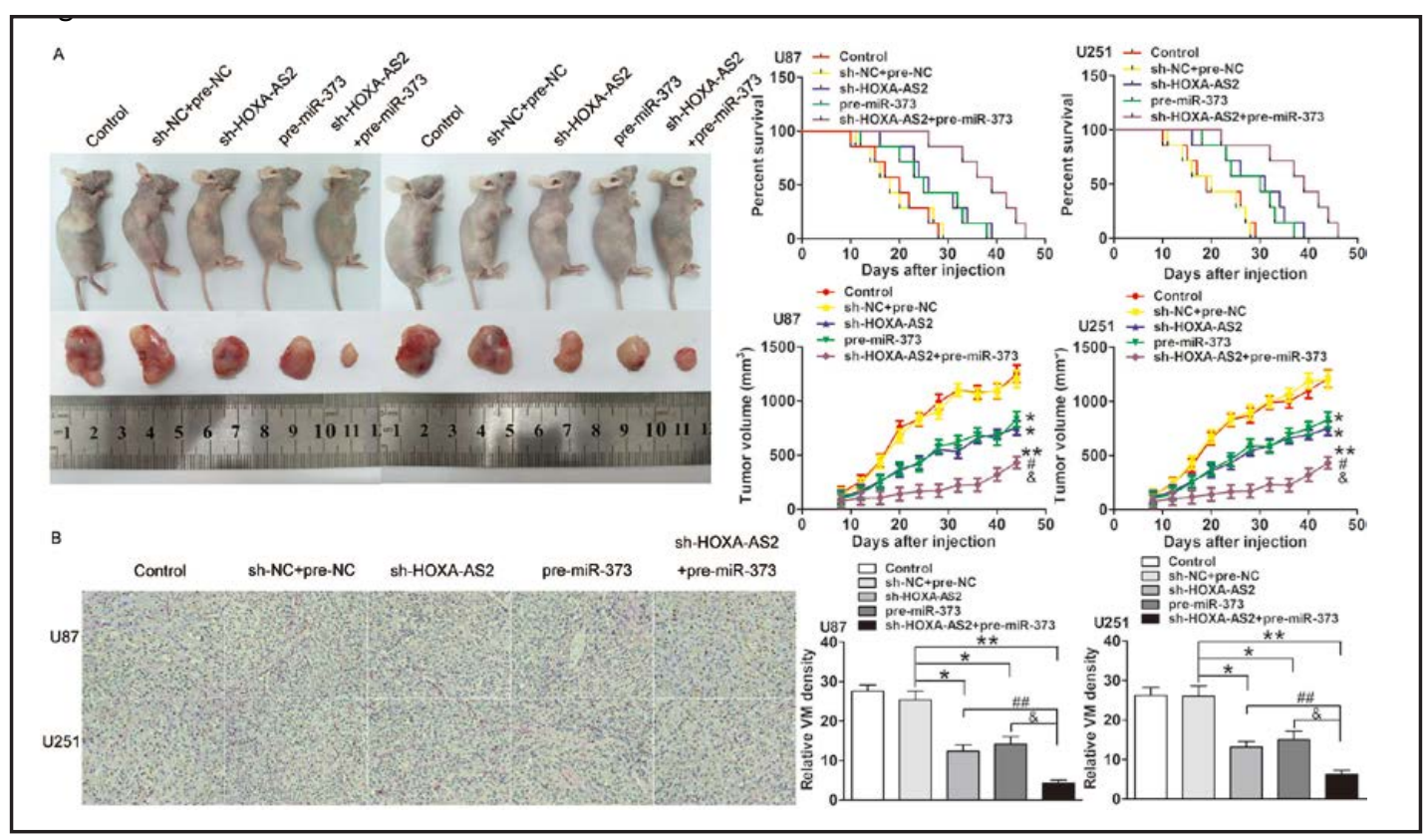

Fig. 7. HOXA-AS2 knockdown combined with miR-373 overexpression suppressed tumor growth and glioma VM formation in vivo. (A) Effect of HOXA-AS2 knockdown, miR-373 overexpression and combination of HOXA-AS2 knockdown and miR-373 overexpression on glioma xenograft volume and nude mice survival. Data represent mean \pm SD. $\left(n=7\right.$, each). ${ }^{*} \mathrm{P}<0.05$ v.s. sh-NC+pre-NC groups, ${ }^{* *} \mathrm{P}<0.01$ v.s. sh-NC+pre-NC groups, ${ }^{\#} \mathrm{P}<0.05$ v.s. sh-HOXA-AS2 groups. ${ }^{\circledR} \mathrm{P}<0.05$ vs pre-miR-373 groups. (B) Effect of HOXA-AS2 knockdown, miR373 overexpression and combination of HOXA-AS2 knockdown and miR-373 overexpression on glioma xenograft VM density. Data were presented as mean \pm SD from four independent experiments. ${ }^{*} \mathrm{P}<0.05$, ${ }^{* *} \mathrm{P}<0.01,{ }^{\# \#} \mathrm{P}<0.01,{ }^{\&} \mathrm{P}<0.05$.

transfection efficiency of EGFR was show in Fig. 6 A. As shown in Fig. 6 B, in U87 and U251 cells, VM tube formation was promoted in the EGFR overexpression groups, and a significant decrease in VM tube formation was observed in the sh-EGFR group. Mechanism research showed that EGFR overexpression increased the expression levels of VE-cadherin, as well as the expression and activity levels of MMP-2 and MMP-9, via activating the PI3K/AKT pathway (Fig. 6 C); these effects could be blocked by using a PI3K inhibitor. In addition, the combination of EGFR knockdown and a PI3K inhibitor had the strongest inhibitory effects on VE-cadherin, MMP-2, and MMP-9 (Fig. 6 D-F).

HOXA-AS2 knockdown combined with miR-373 overexpression yielded optimal tumorsuppressive effects and the lowest VM density in vivo

A subcutaneous xenograft study and an orthotopic xenograft study were performed to further confirm the above findings. As shown in Fig. 7 A, there were no significant differences in the average volumes of the xenograft gliomas between the control and sh$\mathrm{NC}+$ pre-NC groups. The average xenograft volume was smaller in the sh-HOXA-AS2 group, pre-miR-373 groups, and sh-HOXA-AS2 + pre-miR-373 groups. Among all the groups, the sh-HOXA-AS2 + pre-miR-373 groups had the smallest tumor volumes. Similar to the results of the subcutaneous xenograft study, the orthotopic xenograft study showed that mice in the sh-HOXA-AS2 + pre-miR-373 group had the longest survival time. Moreover, CD34-PAS dualstaining showed that xenograft gliomas in the sh-HOXA-AS2 + pre-miR-373 group had the lowest VM densities (Fig. 7 B).

\section{Discussion}

In the present study, we found that IncRNA HOXA-AS2 was upregulated in glioma samples and glioma cell lines. Moreover, there was a positive correlation between HOXA-AS2

\section{KARGER}




\section{\begin{tabular}{ll} 
Cellular Physiology & Cell Physiol Biochem 2018;45:131-147 \\
\hline DOI: 10.1159/000486253 & | 2018 The Author(s). Published by S. Karger AG, Basel
\end{tabular}

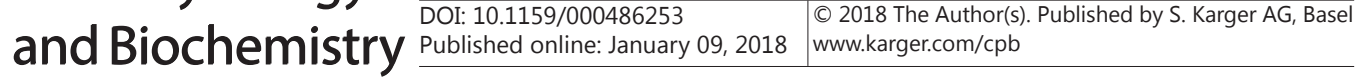

expression levels and glioma VM. HOXA-AS2 knockdown inhibited cell viability, migration, invasion, and VM formation in glioma cells. In contrast, miR-373 was downregulated and exerted a tumor suppressive role in glioma cells. EGFR was found to be a target of miR-373. HOXA-AS2 knockdown decreased EGFR expression levels via binding to and upregulating miR-373. EGFR promoted the expression of VE-cadherin, as well as increased the expression and activity levels of MMP-2 and MMP-9, through activating the PI3K/AKT pathway. Fig. 8 shows the underlying mechanism of the HOXA-AS2/miR-373/EGFR pathway in the regulation of U87 and U251 malignant cell behaviors and VM formation.

Recently, a growing number of publications have shown that lncRNAs are deregulated in malignant tumors and participate in carcinogenesis [20,21]. In addition, IncRNAs also modulate glioma biology, such as migration, invasion, angiogenesis, and drug resistance [10, $11,22]$. In this study, we demonstrated that IncRNA HOXA-AS2 contributed to cell viability, migration, invasion, and VM formation in glioma cells. Consistent with our findings, HOXAAS2 was proven to facilitate tumor malignancy in several publications. In vitro and in vivo studies [23] showed that HOXA-AS2 overexpression promotes cell proliferation in gastric cancer. In addition, Zhang et al. [24] demonstrated that HOXA-AS2 overexpression promotes tumor cell proliferation and induces epithelial-mesenchymal transition (EMT) in gallbladder carcinoma. It has been confirmed that IncRNAs regulate tumor progression through modulating gene expression at the epigenetic, transcriptional and posttranscriptional levels, in which interaction with miRNAs is important. For instance, HOTAIR epigenetically silences miR-34a, leading to enhanced EMT in human gastric cancer [25], and MIR31HG exhibits oncogenic properties by sponging miR-193bin pancreatic ductal adenocarcinoma [26]. Our results showed that HOXA-AS2 negatively regulated miR-373 expression by sponging it. Xie et al. [23] showed that HOXA-AS2 epigenetically silences P21, PLK3, and DDIT3 in gastric cancer cells via binding to EZH2. Moreover, Ding et al. [13] proved that HOXA-AS2 recruits EZH2 and LSD1 to the $p 21$ and KLF12 promoter regions, which inhibits p21 and KLF12 translation. Accordingly, further investigations of whether other mechanisms are involved in HOXA-AS2-mediated miR-373 expression changes should be performed.

Since the first results in melanoma [27], VM has been identified and proven functional in several types of aggressive tumors, including glioma and glioma xenografts [3, 28-30]. Tumor cells, which line the VM channel, tend to migrate and metastasize to other regions as they are directlyexposed to blood flow [31,32]. VM is an aggressive-tumor-specific phenomenon; thus, treatment targeting VM would have fewer side effects. Liu et al. [5] demonstrated that VM-positive glioma patients have a poorer prognosis than patients with VM-negative gliomas. Ju et al. [9], Huang et al. [33], and Ying et al. [34] proved that liposomes containing VM-targeting drugs improve anti-glioma therapy in orthotopic glioma-bearing nude mice. In agreement with the above findings, our in vitro and in vivo results showed that the destruction of VM formation by HOXA-AS2 knockdown impaired glioma malignancy.

VE-cadherin, MMP-2, and MMP-9 were proven to contribute considerably to VM formation. Tumor cells that generate VM express genes that used to be considered specific to endothelial cells, epithelial cells, and fibroblasts $[35,36]$. Among these genes, VE-cadherin is a key modulator of VM [37]. VE-cadherin deficiency decreases VM tube formation in melanoma [38]. In addition, VE-cadherin mediates the cleavage of the laminin $5 \gamma 2$ chain, which may result in VM formation $[39,40]$. Recent studies showed

Fig. 8. The Schematic representation of the mechanism underlying the HOXA/AS2-miR-373/ EGFR axis in U87 and U251 cells.

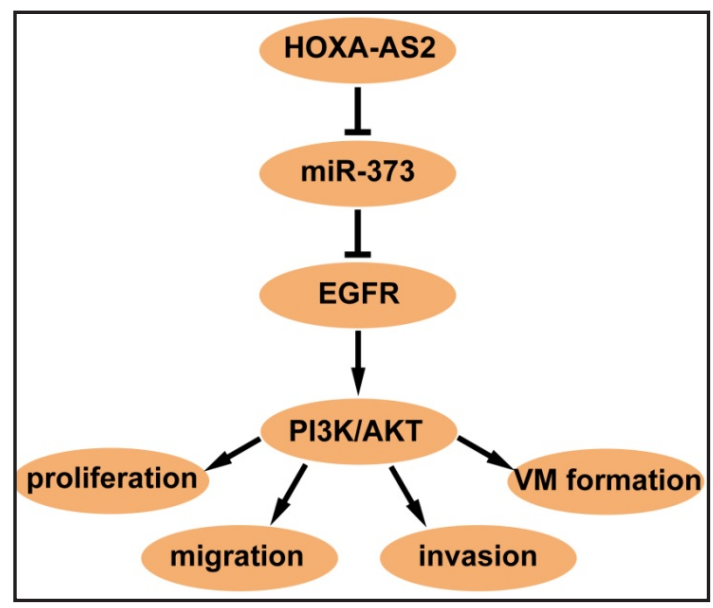




\section{Cellular Physiology Cell Physiol Biochem 2018:45:131-147

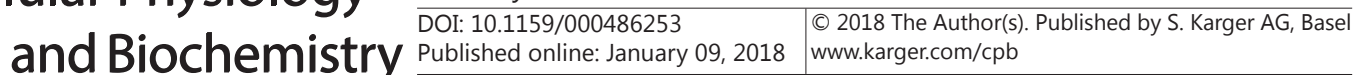 \\ Gao et al.: HOXA-AS2 Regulates Glioma Behaviors and VM Formation}

that VE-cadherin plays prominent roles in glioma VM formation [41, 42]. Furthermore, MMPs enhance extracellular matrixde gradation, which is related to migration, metastasis, and VM formation in tumor cells. In ovarian cancer cells, MMP-2 and MMP-9 have been shown to be upregulated and activated in CD147-induced VM formation [43]. Moreover, MMP-2 and MMP9 mRNA and protein levels are downregulated in the Rg3-mediated inhibition of pancreatic cancer VM formation [44]. In the present study, we proved that VE-cadherin, MMP-2, and MMP-9 were involved in HOXA-AS2-mediated glioma VM formation. Certainly, the precise mechanism needs to be comprehensively explored.

miR-373 functions as either an oncogene or a tumor suppressor in certain types of cancer. For example, miR-373 acts as an oncogene in cervical cancer [45] and esophageal squamous cell carcinoma [46]. However, miR-373 is downregulated in epithelial ovarian cancer [47] and pancreatic cancer [48] and exerts tumor-suppressive effects. In this study, we found that miR-373 played a tumor suppressor role in human glioma through targeting EGFR. Associations between miRNAs and VM were also confirmed by previous studies. Zhao et al. [49] showed that miR-186 regulates prostate cancer VM formation via targeting Twist1. In addition, Wan et al. [50] demonstrated that miR-124 overexpression suppresses VM formation by inhibiting amotL1 expression in cervical cancer cells. Moreover, miR-26b [51], miR-9 [52], and miR-let-7f [53] were reported to inhibit glioma VM formation. Consistent with this evidence, the results in this study showed that the ectopic expression of miR-373 reduced VM formation in U87 and U251 glioma cells. Wei et al. [54] showed that miR-373 inhibits U251 glioma cell migration and invasion but does not affect proliferation in U251 cells. However, our results showed that miR-373 suppressed malignant behaviors inU87 and U251 cells, including cell viability. These disparate results may be attributed to the different assay systems.

EGFR is a widely studied receptor-tyrosine kinase in experimental tumor studies and clinical treatment. Recent findings showed that EGFR is involved in tumor VM formation. An in vitro study by Lee et al. [55] demonstrated that inhibiting EGFR phosphorylation or EGFR knockdown suppresses VM formation in breast cancer stem/progenitor cells (BCSCs). In addition, Tu et al. [56] confirmed that hinokitiol decreases EGFR protein stability, leading to the destruction of VM in BCSCs. EGFR also regulates glioma VM formation. Zhang et al. [57] proposed that the inhibitory effects of LRIG1 on glioma VM formation are most likely mediated by the suppression of the EGFR/PI3K/AKT pathway. In this research, we demonstrated that EGFR enhanced glioma VM formation via increasing the expression levels of VE-cadherin, as well as the expression and activity levels of MMP-2 and MMP-9. Previous studies have shown that EGFR regulates VE-cadherin, MMP-2, and MMP-9 expression and function via the PI3K/AKT pathway, MEK/ERK pathway, and AKT pathway [58, 59]. The present study showed that EGFR increased VE-cadherin expression levels and MMP-2 and MMP-9 expression and activity levels via activating the PI3K/AKT pathway.

\section{Conclusion}

This study found for the first time that HOXA-AS2 was upregulated in glioma samples and cell lines and was positively associated with glioma VM. HOXA-AS2 knockdown remarkably inhibited glioma malignancy and VM formation and the expression of EGFR by upregulating miR-373. These findings may provide new insights into glioma treatment.

\section{Disclosure Statement}

The authors declare that they have no competing interests.

\section{Acknowledgements}

This work is supported by grants from the Natural Science Foundation of China (Nos. 81573010, 81372484 and 81672511), Liaoning Science and Technology Plan Project (No. 


\section{Cellular Physiology Cell Physiol Biochem 2018:45:131-147 \begin{tabular}{l|l|l} 
and Biochemistry 10.1159/000486253 & $\begin{array}{l}\text { C } 2018 \text { The Author(s). Published by S. Karger AG, Basel } \\
\text { www.karger.com/cpb }\end{array}$
\end{tabular}}

Gao et al.: HOXA-AS2 Regulates Glioma Behaviors and VM Formation

2015225007), Special developmental project guided by central government of Liaoning Province (No.2017011553-301), Special fund for Scientific Research of Doctor-degree Subjects in Colleges and Universities (No. 201601123).

YX and YL conceived and designed the project. YG and WG performed most of the experiments. JZ and JC acquired clinical data and did statistics analysis. YH and XL wrote the manuscript. YT and LZ did animal experiments and Western blotting experiments. YX and YL contributed to the manuscript revision.

\section{References}

1 Stupp R, Hegi ME, Mason WP, van den Bent MJ, Taphoorn MJ, Janzer RC, Ludwin SK, Allgeier A, Fisher B, Belanger K, Hau P, Brandes AA, Gijtenbeek J, Marosi C, Vecht CJ, Mokhtari K, Wesseling P, Villa S, Eisenhauer E, Gorlia T, Weller M, Lacombe D, Cairncross JG, Mirimanoff RO, European Organisation for R, Treatment of Cancer Brain T, Radiation Oncology G, National Cancer Institute of Canada Clinical Trials G: Effects of radiotherapy with concomitant and adjuvant temozolomide versus radiotherapy alone on survival in glioblastoma in a randomised phase III study: 5-year analysis of the EORTC-NCIC trial. Lancet Oncol 2009;10:459-466.

- Kreisl TN, Kim L, Moore K, Duic P, Royce C, Stroud I, Garren N, Mackey M, Butman JA, Camphausen K, Park J, Albert PS, Fine HA: Phase II trial of single-agent bevacizumab followed by bevacizumab plus irinotecan at tumor progression in recurrent glioblastoma. J Clin Oncol 2009;27:740-745.

-3 Yue WY, Chen ZP: Does vasculogenic mimicry exist in astrocytoma? J Histochem Cytochem 2005;53:9971002.

4 El Hallani S, Boisselier B, Peglion F, Rousseau A, Colin C, Idbaih A, Marie Y, Mokhtari K, Thomas JL, Eichmann A, Delattre JY, Maniotis AJ, Sanson M: A new alternative mechanism in glioblastoma vascularization: tubular vasculogenic mimicry. Brain 2010;133:973-982.

5 Liu XM, Zhang QP, Mu YG, Zhang XH, Sai K, Pang JC, Ng HK, Chen ZP: Clinical significance of vasculogenic mimicry in human gliomas. J Neurooncol 2011;105:173-179.

6 Chen Y, Jing Z, Luo C, Zhuang M, Xia J, Chen Z, Wang Y: Vasculogenic mimicry-potential target for glioblastoma therapy: an in vitro and in vivo study. Med Oncol 2012;29:324-331.

-7 van der Schaft DW, Seftor RE, Seftor EA, Hess AR, Gruman LM, Kirschmann DA, Yokoyama Y, Griffioen AW, Hendrix MJ: Effects of angiogenesis inhibitors on vascular network formation by human endothelial and melanoma cells. J Natl Cancer Inst 2004;96:1473-1477.

8 Folkman J: Angiogenesis: an organizing principle for drug discovery? Nat Rev Drug Discov 2007;6:273-286.

9 Ju RJ, Zeng F, Liu L, Mu LM, Xie HJ, Zhao Y, Yan Y, Wu JS, Hu YJ, Lu WL: Destruction of vasculogenic mimicry channels by tałgeting epirubicin plus celecoxib liposomes in treatment of brain glioma. Int J Nanomedicine 2016;11:1131-1146.

10 Cai H, Liu X, Zheng J, Xue Y, Ma J, Li Z, Xi Z, Li Z, Bao M, Liu Y: Long non-coding RNA taurine upregulated 1 enhances tumor-induced angiogenesis through inhibiting microRNA-299 in human glioblastoma. Oncogene 2017;36:318-331.

-11 Teng H, Wang P, Xue Y, Liu X, Ma J, Cai H, Xi Z, Li Z, Liu Y: Role of HCP5-miR-139-RUNX1 Feedback Loop in Regulating Malignant Behavior of Glioma Cells. Mol Ther 2016;24:1806-1822.

12 Zhao H, Zhang X, Frazao JB, Condino-Neto A, Newburger PE: HOX antisense lincRNA HOXA-AS2 is an apoptosis repressor in all trans retinoic acid treated NB4 promyelocytic leukemia cells. J Cell Biochem 2013;114:2375-2383.

13 Ding J, Xie M, Lian Y, Zhu Y, Peng P, Wang J, Wang L, Wang K: Long noncoding RNA HOXA-AS2 represses P21 and KLF2 expression transcription by binding with EZH2, LSD1 in colorectal cancer. Oncogenesis 2017;6:e288.

14 Wang F, Yang H, Deng Z, Su Y, Fang Q, Yin Z: HOX Antisense lincRNA HOXA-AS2 Promotes Tumorigenesis of Hepatocellular Carcinoma. Cell Physiol Biochem 2016;40:287-296.

15 Swartz AM, Li QJ, Sampson JH: Rindopepimut: a promising immunotherapeutic for the treatment of glioblastoma multiforme. Immunotherapy 2014;6:679-690.

-16 Sampson JH, Heimberger AB, Archer GE, Aldape KD, Friedman AH, Friedman HS, Gilbert MR, Herndon JE, 2nd, McLendon RE, Mitchell DA, Reardon DA, Sawaya R, Schmittling RJ, Shi W, Vredenburgh JJ, Bigner DD: Immunologic escape after prolonged progression-free survival with epidermal growth factor receptor variant III peptide vaccination in patients with newly diagnosed glioblastoma. J Clin Oncol 2010;28:4722- 


\section{Cellular Physiology Cell Physiol Biochem 2018;45:131-147

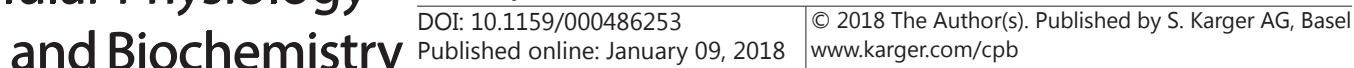

Gao et al.: HOXA-AS2 Regulates Glioma Behaviors and VM Formation

4729.

17 Paulis YW, Soetekouw PM, Verheul HM, Tjan-Heijnen VC, Griffioen AW: Signalling pathways in vasculogenic mimicry. Biochim Biophys Acta 2010;1806:18-28.

18 Bartel DP: MicroRNAs: target recognition and regulatory functions. Cell 2009;136:215-233.

19 Feng H, Hu B, Vuori K, Sarkaria JN, Furnari FB, Cavenee WK, Cheng SY: EGFRvIII stimulates glioma growth and invasion through PKA-dependent serine phosphorylation of Dock180 Oncogene 2014;33:2504-2512.

20 Yang Y, Chen L, Gu J, Zhang H, Yuan J, Lian Q, Lv G, Wang S, Wu Y, Yang YT, Wang D, Liu Y, Tang J, Luo G, Li Y, Hu L, Sun X, Wang D, Guo M, Xi Q, Xi J, Wang H, Zhang MQ, Lu ZJ: Recurrently deregulated IncRNAs in hepatocellular carcinoma. Nat Commun 2017;8:14421.

-21 McCleland ML, Mesh K, Lorenzana E, Chopra VS, Segal E, Watanabe C, Haley B, Mayba O, Yaylaoglu M, Gnad F, Firestein R: CCAT1 is an enhancer-templated RNA that predicts BET sensitivity in colorectal cancer. J Clin Invest 2016;126:639-652.

22 Jiang P, Wang P, Sun X, Yuan Z, Zhan R, Ma X, Li W: Knockdown of long noncoding RNA H19 sensitizes human glioma cells to temozolomide therapy. Onco Targets Ther 2016;9:3501-3509.

-23 Xie M, Sun M, Zhu YN, Xia R, Liu YW, Ding J, Ma HW, He XZ, Zhang ZH, Liu ZJ, Liu XH, De W: Long noncoding RNA HOXA-AS2 promotes gastric cancer proliferation by epigenetically silencing P21/PLK3/DDIT3 expression. Oncotarget 2015;6:33587-33601.

24 Zhang P, Cao P, Zhu X, Pan M, Zhong K, He R, Li Y, Jiao X, Gao Y: Upregulation of long non-coding RNA HOXAAS2 promotes proliferation and induces epithelial-mesenchymal transition in gallbladder carcinoma. Oncotarget 2017;8:33137-33143.

25 Liu YW, Sun M, Xia R, Zhang EB, Liu XH, Zhang ZH, Xu TP, De W, Liu BR, Wang ZX: LincHOTAIR epigenetically silences miR34a by binding to PRC2 to promote the epithelial-to-mesenchymal transition in human gastric cancer. Cell Death Dis 2015;6:e1802.

-26 Yang H, Liu P, Zhang J, Peng X, Lu Z, Yu S, Meng Y, Tong WM, Chen J: Long noncoding RNA MIR31HG exhibits oncogenic property in pancreatic ductal adenocarcinoma and is negatively regulated by miR-193b. Oncogene 2016;35:3647-3657.

27 Maniotis AJ, Folberg R, Hess A, Seftor EA, Gardner LM, Pe'er J, Trent JM, Meltzer PS, Hendrix MJ: Vascular channel formation by human melanoma cells in vivo and in vitro: vasculogenic mimicry. Am J Pathol 1999;155:739-752.

28 Shirakawa K, Kobayashi H, Heike Y, Kawamoto S, Brechbiel MW, Kasumi F, Iwanaga T, Konishi F, Terada $\mathrm{M}$, Wakasugi H: Hemodynamics in vasculogenic mimicry and angiogenesis of inflammatory breast cancer xenograft. Cancer Res 2002;62:560-566.

29 Guzman G, Cotler SJ, Lin AY, Maniotis AJ, Folberg R: A pilot study of vasculogenic mimicry immunohistochemical expression in hepatocellular carcinoma. Arch Pathol Lab Med 2007;131:1776-1781.

30 Zhang C, Chen W, Zhang X, Huang B, Chen A, He Y, Wang J, Li X: Galunisertib inhibits glioma vasculogenic mimicry formation induced by astrocytes. Sci Rep 2016;6:23056.

31 Shirakawa K, Wakasugi H, Heike Y, Watanabe I, Yamada S, Saito K, Konishi F: Vasculogenic mimicry and pseudo-comedo formation in breast cancer. Int J Cancer 2002;99:821-828.

-32 Sun B, Zhang S, Zhang D, Du J, Guo H, Zhao X, Zhang W, Hao X: Vasculogenic mimicry is associated with high tumor grade, invasion and metastasis, and short survival in patients with hepatocellular carcinoma. Oncol Rep 2006;16:693-698.

-33 Huang D, Zhang S, Zhong T, Ren W, Yao X, Guo Y, Duan XC, Yin YF, Zhang SS, Zhang X: Multi-targeting NGRmodified liposomes recognizing glioma tumor cells and vasculogenic mimicry for improving anti-glioma therapy. Oncotarget 2016;7:43616-43628.

34 Ying M, Zhan C, Wang S, Yao B, Hu X, Song X, Zhang M, Wei X, Xiong Y, Lu W: Liposome-Based Systemic Glioma-Targeted Drug Delivery Enabled by All-d Peptides. ACS Appl Mater Interfaces 2016;8:29977-29985.

-35 Bittner M, Meltzer P, Chen Y, Jiang Y, Seftor E, Hendrix M, Radmacher M, Simon R, Yakhini Z, Ben-Dor A, Sampas N, Dougherty E, Wang E, Marincola F, Gooden C, Lueders J, Glatfelter A, Pollock P, Carpten J, Gillanders E, Leja D, Dietrich K, Beaudry C, Berens M, Alberts D, Sondak V: Molecular classification of cutaneous malignant melanoma by gene expression profiling. Nature 2000;406:536-540.

-36 Seftor EA, Meltzer PS, Kirschmann DA, Pe'er J, Maniotis AJ, Trent JM, Folberg R, Hendrix MJ: Molecular determinants of human uveal melanoma invasion and metastasis. Clin Exp Metastasis 2002;19:233-246.

-37 Delgado-Bellido D, Serrano-Saenz S, Fernandez-Cortes M, Oliver FJ: Vasculogenic mimicry signaling revisited: focus on non-vascular VE-cadherin. Mol Cancer 2017;16:65. 


\section{Cellular Physiology Cell Physiol Biochem 2018;45:131-147 \begin{tabular}{ll|l} 
DOI: 10.1159/000486253 & Ond 2018 The Author(s). Published by S. Karger AG, Basel \\
wwww.karger.com/cpb
\end{tabular}}

Gao et al.: HOXA-AS2 Regulates Glioma Behaviors and VM Formation

-38 Hendrix MJ, Seftor EA, Meltzer PS, Gardner LM, Hess AR, Kirschmann DA, Schatteman GC, Seftor RE: Expression and functional significance of VE-cadherin in aggressive human melanoma cells: role in vasculogenic mimicry. Proc Natl Acad Sci U S A 2001;98:8018-8023.

-39 Hess AR, Seftor EA, Seftor RE, Hendrix MJ: Phosphoinositide 3-kinase regulates membrane Type 1-matrix metalloproteinase (MMP) and MMP-2 activity during melanoma cell vasculogenic mimicry. Cancer Res 2003;63:4757-4762.

40 Seftor RE, Seftor EA, Kirschmann DA, Hendrix MJ: Targeting the tumor microenvironment with chemically modified tetracyclines: inhibition of laminin 5 gamma2 chain promigratory fragments and vasculogenic mimicry. Mol Cancer Ther 2002;1:1173-1179.

41 Ling G, Wang S, Song Z, Sun X, Liu Y, Jiang X, Cai Y, Du M, Ke Y: Transforming growth factor-beta is required for vasculogenic mimicry formation in glioma cell line U251MG. Cancer Biol Ther 2011;12:978-988.

-42 Nissou MF, El Atifi M, Guttin A, Godfraind C, Salon C, Garcion E, van der Sanden B, Issartel JP, Berger F, Wion D: Hypoxia-induced expression of VE-cadherin and filamin B in glioma cell cultures and pseudopalisade structures. J Neurooncol 2013;113:239-249.

43 Millimaggi D, Mari M, S DA, Giusti I, Pavan A, Dolo V: Vasculogenic mimicry of human ovarian cancer cells: role of CD147 Int J Oncol 2009;35:1423-1428.

44 Guo JQ Zheng QH, Chen H, Chen L, Xu JB, Chen MY, Lu D, Wang ZH, Tong HF, Lin S: Ginsenoside Rg3 inhibition of vasculogenic mimicry in pancreatic cancer through downregulation of VEcadherin/EphA2/ MMP9/MMP2 expression. Int J Oncol 2014;45:1065-1072.

45 Wang LQ, Zhang Y, Yan H, Liu KJ, Zhang S: MicroRNA-373 functions as an oncogene and targets YOD1 gene in cervical cancer. Biochem Biophys Res Commun 2015;459:515-520.

46 Liu W, Li M, Chen X, Zhang D, Wei L, Zhang Z, Wang S, Meng L, Zhu S, Li B: MicroRNA-373 promotes migration and invasion in human esophageal squamous cell carcinoma by inhibiting TIMP3 expression. Am J Cancer Res 2016;6:1-14.

47 Zhang Y, Zhao FJ, Chen LL, Wang LQ Nephew KP, Wu YL, Zhang S: MiR-373 targeting of the Rab22a oncogene suppresses tumor invasion and metastasis in ovarian cancer. Oncotarget 2014;5:12291-12303.

48 Nakata K, Ohuchida K, Mizumoto K, Aishima S, Oda Y, Nagai E, Tanaka M: Micro RNA-373 is down-regulated in pancreatic cancer and inhibits cancer cell invasion. Ann Surg Oncol 2014;21 Suppl 4:S564-574.

49 Zhao X, Wang Y, Deng R, Zhang H, Dou J, Yuan H, Hou G, Du Y, Chen Q, Yu J: miR186 suppresses prostate cancer progression by targeting Twist1 Oncotarget 2016;7:33136-33151.

50 Wan HY, Li QQ, Zhang Y, Tian W, Li YN, Liu M, Li X, Tang H: MiR-124 represses vasculogenic mimicry and cell motility by targeting amotL1 in cervical cancer cells. Cancer Lett 2014;355:148-158.

-51 Wu N, Zhao X, Liu M, Liu H, Yao W, Zhang Y, Cao S, Lin X: Role of microRNA-26b in glioma development and its mediated regulation on EphA2 PLoS One 2011;6:e16264.

52 Song Y, Mu L, Han X, Li Q, Dong B, Li H, Liu X: MicroRNA-9 inhibits vasculogenic mimicry of glioma cell lines by suppressing Stathmin expression. J Neurooncol 2013;115:381-390.

53 Xue H, Gao X, Xu S, Zhang J, Guo X, Yan S, Li T, Guo X, Liu Q Li G: MicroRNA-Let-7f reduces the vasculogenic mimicry of human glioma cells by regulating periostin-dependent migration. Oncol Rep 2016;35:17711777.

54 Wei F, Wang Q, Su Q Huang H, Luan J, Xu X, Wang J: miR-373 Inhibits Glioma Cell U251 Migration and Invasion by Down-Regulating CD44 and TGFBR2Ｃell Mol Neurobiol 2016;36:1389-1397.

-55 Lee CH, Wu YT, Hsieh HC, Yu Y, Yu AL, Chang WW: Epidermal growth factor/heat shock protein 27 pathway regulates vasculogenic mimicry activity of breast cancer stem/progenitor cells. Biochimie 2014;104:117126.

-56 Tu DG, Yu Y, Lee CH, Kuo YL, Lu YC, Tu CW, Chang WW: Hinokitiol inhibits vasculogenic mimicry activity of breast cancer stem/progenitor cells through proteasome-mediated degradation of epidermal growth factor receptor. Oncol Lett 2016;11:2934-2940.

57 Zhang X, Song Q Wei C, Qu J: LRIG1 inhibits hypoxia-induced vasculogenic mimicry formation via suppression of the EGFR/PI3K/AKT pathway and epithelial-to-mesenchymal transition in human glioma SHG-44 cells. Cell Stress Chaperones 2015;20:631-641.

58 Hung MS, Chen IC, Lung JH, Lin PY, Li YC, Tsai YH: Epidermal Growth Factor Receptor Mutation Enhances Expression of Cadherin-5 in Lung Cancer Cells. PLoS One 2016;11:e0158395.

-59 Xiao LJ, Lin P, Lin F, Liu X, Qin W, Zou HF, Guo L, Liu W, Wang SJ, Yu XG: ADAM17 targets MMP-2 and MMP-9 via EGFR-MEK-ERK pathway activation to promote prostate cancer cell invasion. Int J Oncol 2012;40:17141724. 